\title{
Quem são os alunos matriculados em uma universidade pública federal?
}

Who are the students enrolled in a federal public university?

¿Quiénes son los estudiantes matriculados en una universidad pública federal?

Juliana Monteiro Maia

ORCID: https://orcid.org/0000-0002-2461-2103 Universidade Federal Rural da Amazônia, Brasil E-mail: julianamaia.agro@gmail.com

Bruna Nascimento Vicenzott ORCID: https://orcid.org/0000-0001-5078-3582 Universidade Federal Rural da Amazônia, Brasil

E-mail: bruna.nascimento.vicenzott@hotmail.com

Josilene do Nascimento Gomes ORCID: https://orcid.org/0000-0001-8077-5153 Universidade Federal Rural da Amazônia, Brasil E-mail: josilenegomespgm@gmail.com

Sara Souza de Jesus de Oliveira ORCID: https://orcid.org/0000-0003-1879-9335 Universidade Federal Rural da Amazônia, Brasil E-mail: sara.jesus0303@gmail.com

Sebastião Rodrigo do Remédio Souza de Oliveira ORCID: https://orcid.org/0000-0002-9498-8237 Universidade Federal Rural da Amazônia, Brasil E-mail: rodrigosouza6789@gmail.com

Wenderson da Silva Rodrigues ORCID: https://orcid.org/ 0000-0002-7276-2050 Universidade Federal Rural da Amazônia, Brasil E-mail: wendersonr306@gmail.com

Alessandra Epifanio Rodrigues ORCID: https://orcid.org/0000-0002-8375-2923 Universidade Federal Rural da Amazônia, Brasil E-mail: alessandra.epifanio@ufra.edu.br

Ana Paula Ignácio Pontes Leal ORCID: https://orcid.org/0000-0002-8733-0066 Universidade Federal Rural da Amazônia, Brasil E-mail: paula.ignacio@ufra.edu.br

Aneska Silva de Oliveira ORCID: https://orcid.org/0000-0001-9852-0407 Universidade Federal Rural da Amazônia, Brasil E-mail: aneskapsi@gmail.com

Bárbara Rodrigues de Quadros ORCID: https://orcid.org/0000-0001-7052-4326 Universidade Federal Rural da Amazônia, Brasil E-mail: barbara.quadros@ufra.edu.br

Izabelle Pereira Andrade ORCID: https://orcid.org/ 0000-0002-7577-5033 Universidade Federal Rural da Amazônia, Brasil E-mail: izabelle.andrade@ufra.edu.br

Mônica Calixto da Silva ORCID: https://orcid.org/0000-0002-7546-6708 Universidade Federal Rural da Amazônia, Brasil E-mail: monica.calixto@ufra.edu.br

Vanessa Mayara Souza Pamplona ORCID: https://orcid.org/0000-0002-2461-2103 Universidade Federal Rural da Amazônia, Brasil E-mail: vanessa.pamplona@ufra.edu.br

\section{Resumo}

Mapear o perfil de estudantes que adentram as universidades públicas já é um objetivo de diversos estudos, porém esse perfil tem se apresentado cada vez mais singular. Desta forma, buscamos neste estudo levantar indicadores que nos auxiliem na compreensão da realidade e das particularidades dos estudantes dos diferentes cursos do ensino superior de uma universidade pública federal do sudeste paraense, por meio do diagnóstico socioeconômico destes alunos. Neste 
artigo, utiliza-se, um questionário estruturado, com perguntas diretas, calculando-se uma amostra estratificada por curso e turma/semestre, considerando o nível de significância igual a 5\%, com base na quantidade de alunos matriculados no $2^{\circ}$ semestre de 2019, o que totalizou uma amostra de 251 alunos. Dentre os principais resultados, destaca-se no estudo, a predominância de alunos do sexo feminino, que se autodeclararam pardos, sem deficiência, que moram com os pais em casa própria, dependem de transporte público, sem vínculo empregatício, não recebem nenhum benefício de programa social do governo federal e não participam de atividades extracurriculares. Com isso, entende-se algumas características predominantes no ambiente acadêmico e que influenciam no desempenho e estabilidade dos estudantes na universidade, assim se torna mais viável elaborar políticas de permanência e que favoreçam a aprendizagem destes estudantes no ensino superior.

Palavras-chave: Diagnóstico socioeconômico; Políticas de permanência; Ambiente acadêmico.

\begin{abstract}
Mapping the profile of students entering public universities is already an objective of several studies, but this profile has been increasingly unique. Thus, we seek in this study to raise indicators that help us in understanding the reality and particularities of students of different higher education courses of a federal public university in southeastern Pará, through the socioeconomic diagnosis of these students. In this article, a structured questionnaire with direct questions is used, calculating a stratified sample per course and class/semester, considering the level of significance equal to 5\%, based on the number of students enrolled in the 2nd semester of 2019, which totaled a sample of 251 students. Among the main results, the predominance of female students, who declared themselves brown, without disabilities, who live with their parents in their own homes, depend on public transportation, no employment relationship, do not receive any social program benefit from the federal government and do not participate in extracurricular activities. Thus, some characteristics prevailing in the academic environment are understood and that influence the performance and stability of students at the university, thus it becomes more feasible to develop policies of permanence and that favor the learning of these students in higher education.
\end{abstract}

Keywords: Socioeconomic diagnosis; Policies of permanence; Academic environment.

\title{
Resumen
}

Mapear el perfil de los estudiantes que ingresan a las universidades públicas ya es un objetivo de varios estudios, pero este perfil ha sido cada vez más único. Por lo tanto, buscamos en este estudio elevar indicadores que nos ayuden a comprender la realidad y las particularidades de los estudiantes de diferentes cursos de educación superior de una universidad pública federal en el sureste de Pará, a través del diagnóstico socioeconómico de estos estudiantes. En este artículo se utiliza un cuestionario estructurado con preguntas directas, calculando una muestra estratificada por curso y clase/semestre, considerando el nivel de significación igual al 5\%, en base al número de estudiantes matriculados en el $2^{\circ}$ semestre de 2019, que totalizó una muestra de 251 estudiantes. Entre los principales resultados, el predominio de las estudiantes, que se declararon morenas, sin discapacidad, que viven con sus padres en sus propios hogares, dependen del transporte público, no tienen relación laboral, no reciben ningún beneficio del programa social del gobierno federal y no participan en actividades extracurriculares. Así, se entienden algunas características que prevalecen en el entorno académico y que influyen en el desempeño y la estabilidad de los estudiantes en la universidad, por lo que se hace más factible desarrollar políticas de permanencia y que favorezcan el aprendizaje de estos estudiantes en la educación superior.

Palabras clave: Diagnóstico socioeconómico; Políticas de permanencia; Entorno académico.

\section{Introdução}

Nas últimas décadas aumentou-se consideravelmente o número de novas instituições públicas de ensino superior no Brasil. Inúmeros fatores contribuíram para essa expansão, mas, principalmente, as políticas públicas implementadas pelo governo federal e o mercado de trabalho, que se passou a exigir cada vez mais qualificação profissional (Agapito, 2016). Esses dois fatores, foram fortes influenciadores para que mesmo aquelas pessoas que já estavam inseridas no mercado de trabalho, retornassem para as salas de aulas.

O levantamento realizado, desde 1996 até 2018, pelo Fórum Nacional de Pró-reitores de Assuntos Culturais e Estudantis (FONAPRACE) e pela Associação Nacional dos Dirigentes das Instituições Federais de Ensino Superior (ANDIFES) tem o objetivo de descrever sobre o 'perfil médio', demonstrando a situação socioeconômico e cultural dos discentes das instituições federais de ensino superior do Brasil. Desta maneira, indica um relevante papel com o intuito de instrumentalizar os respectivos gestores, permitindo um diagnóstico diretamente relacionado aqueles envolvidos na gestão de políticas estratégicas de desenvolvimento institucional e de assistência estudantil. 
De acordo com Carvalho e Waltenberg (2015) a educação superior proporciona maior capacidade e produtividade, melhor remuneração, além de deixar as pessoas menos expostas ao desemprego. Essa possibilidade de obter melhor qualidade de vida, é norteador para que jovens e adultos cada vez mais, busquem a educação superior.

Entretanto, ainda não há motivos a se comemorar, pois o percentual da população brasileira que consegue ingressar no ensino superior, é pequeno. E muitos dos que conseguem matricular-se, não conseguem concluir. Um dos principais fatores que contribui para a evasão dos estudantes nas Instituições de Ensino Superior (IES) é a desigualdade social, que afeta principalmente jovens pretos, de baixa renda e do sexo masculino, pois muitos deles acabam desistindo para trabalhar, ou porque não consegue custear as despesas geradas durante o decorrer do curso (Rodrigues et al., 2017).

Há alguns anos que estão sendo construídos diversas ações em prol da juventude, com o intuito de minimizar às situações de riscos ligadas a vulnerabilidade, marginalidade e criminalidade. Deste modo, havendo a democratização do acesso ao ensino superior no Brasil, por meio do sistema de cotas, principalmente para realizar a interiorização dos campi das instituições através do Enem/Sisu, e das reservas de vagas para pretos, pardos e indígenas (PPI) e pessoas com deficiência (PCD).

Em 2012, foi sancionada a "Lei de Cotas", Lei No 12.711, de 29 de agosto de 2012, pela primeira mulher presidente da república federativa do Brasil, a excelentíssima senhora Dilma Rousseff (BRASIL, 2012). Essa Lei de Cotas, proporcionou que estudantes de diferentes posições socioeconômicas, idades, gêneros, etnias, cor, tivessem a oportunidade de ingressar nos variados cursos de graduação das Instituições de Ensino Superior (Neves et al., 2018).

A Lei de Cotas dispõe sobre o "ingresso" nas Universidades Federais e nos Institutos Federais de ensino técnico de nível médio mantidos pelo Ministério de Educação (MEC), e garante por meio de cotas a reserva de 50\% dos matriculados serem oriundos de famílias de baixa renda (receber renda igual ou inferior a 1,5 salário mínimo do Estado Brasileiro), bem como àqueles que são autodeclarados pretos, pardos e indígenas. Esta lei foi alterada no ano de 2016, por meio da Lei No 13.409 de 28 de dezembro de 2016, sendo acrescida a estas cotas relacionadas a reserva de vagas para pessoa com deficiência (BRASIL, 2016).

No entanto, fica evidente que apenas políticas de acesso ao ensino superior, não é essencial, é preciso desenvolver programas de assistência e suporte estudantil, para auxiliar que os estudantes tenham condições financeira e psicológica para garantir sua permanência na Instituição e conclusão do curso (Queiroz et al., 2015). Nesse sentindo, programas de incentivos e suporte financeiros, são fundamentais, principalmente para os estudantes de baixa renda.

Com o intuito de reduzir esses impactos das desigualdades entre os alunos, o governo federal criou o Plano de Assistência Estudantil (PNAES), que visa garantir auxílio alimentação, moradia, transporte e creche. O Programa Institucional de Bolsas de Iniciação Científica (PIBIC) que visa estimular o interesse pela pesquisa científica e, promover o desenvolvimento da ciência e tecnologia. Além do Programa de Educação Tutorial (PET), monitorias e estágios remunerados, que estimulam o conhecimento crítico e a permanência dos estudantes no ensino superior.

Os pontos positivos desses programas de assistência estudantil não são apenas auxílio financeiro e sim estimular a permanência dos estudantes nas IES, esses programas despertam o interesse pela pesquisa, proporcionam descobertas, conhecimentos, senso crítico, prepara para o mercado de trabalho, pois, permite ao aluno associar o conhecimento teórico a aplicação prática.

Deste modo, partimos então, para a primeira indagação motivada no Grupo de Estudos e Pesquisas em Estatística Aplicada (GEPEA): "Quem são os alunos matriculados em uma universidade pública federal no sudeste paraense? ”

Nesse sentido, torna-se necessário conhecer a realidade e as particularidades dos estudantes dos diferentes cursos do ensino superior, e identificar os fatores que restringem sua permanência nas IES, para que ações possam ser tomadas, a fim de se reduzir os fatores que favorecem as desistências e aumentam as desigualdades educacionais, garantindo que todos tenham acesso ao conhecimento e ao ensino de qualidade. Diante do exposto, objetivou-se avaliar o diagnóstico socioeconômico de 
alunos de uma universidade pública federal.

\section{Metodologia}

O estudo foi realizado na Universidade Federal Rural da Amazônia (UFRA), campus Paragominas, pelo GEPEA, e faz parte do projeto de pesquisa intitulado "Perfil socioeconômico e cultural dos discentes matriculados na Universidade Federal Rural da Amazônia, campus Paragominas", cadastrado sob o número PIPG266-2017 na Pró reitoria de Pesquisa e Desenvolvimento Tecnológico (PROPED) da UFRA.

Para o estudo foi calculada uma amostra estratificada por curso e turma/semestre, considerando o nível de significância igual a 5\%, com base na quantidade de alunos matriculados no $2^{\circ}$ semestre de 2019, o que totalizou uma amostra de 251 alunos, composta por 44 alunos do curso de Administração (Adm), 69 de Agronomia (Agro), 48 de Engenharia Florestal (Flor), 57 de Zootecnia (Zoo) e 33 de Sistemas de Informação (SI).

Para a coleta de dados foi elaborado um questionário estruturado com perguntas diretas divididas em quatro blocos: i) perfil dos estudantes: (idade, sexo, auto declaração, estado civil e deficiência), ii) dados socioeconômicos dos universitários: (condição e situação de moradia atual, deslocamento até a UFRA, remuneração, situação em relação ao orçamento familiar, recebimento de auxilio acadêmico, participação em programa social, participação em programa acadêmico), iii) dados socioeconômicos da família: (filhos, conjugue, renda familiar em salário mínimo e quantas pessoas dependem da renda) e iv) dados de saúde, lazer/cultural e qualidade de vida: (tratamento de saúde, uso de medicação, frequência em uso de bebidas alcoólicas, tabacos e drogas ilícitas, local de acesso à internet, fonte de lazer na UFRA, atividades físicas, número de refeições, infraestrutura da UFRA, acompanhamento pela PROAES, dificuldades no contexto acadêmico, trancamento de disciplina e/ou curso e por fim as emoções mais frequentes na trajetória acadêmica). Para este artigo foram utilizados somente os dados relacionados ao perfil socioeconômico dos discentes.

Durante a aplicação do questionário levou-se em consideração a preservação do anonimato do discente; em que cada questionário foi preenchido por uma única pessoa, isto é, não foi permitido o preenchimento em equipe.

Após a obtenção dos dados, estes foram organizados em uma planilha eletrônica, onde posteriormente foi realizada a análise exploratória de dados, com o objetivo de resumir as principais características do perfil socioeconômico dos discentes por meio de tabelas, gráficos e medidas descritivas.

\section{Resultados e Discussão}

Observa-se que 59,66\% dos alunos, encontravam-se na faixa etária de 19 a 23 anos, seguido de $16,81 \%$ de 16 a 18 anos (Tabela 1). Diante disso, subentendesse que os jovens estão cada dia mais preocupados em obter qualificação profissional. Natividade (2014) afirma que os anos em que um indivíduo passa estudando, reflete diretamente nas oportunidades que ele terá na sociedade na qual ele vive. Em função disso, acredita-se que a opção de maior anseio dos jovens na contemporaneidade é a continuação de seus estudos, e para tanto, é necessário que haja políticas públicas, que permitam haver igualdade de concorrência, para inserção de maneira geral desses jovens, independente das suas particularidades.

Quando comparado a outros países, pode-se afirmar que o processo de expansão da Educação Superior no Brasil é recente. Apesar das divergências entre os sistemas de ensino, a comparação é válida para identificar o atraso do país em termos educacionais (Tachibana et al., 2015). Nos anos 90, a oferta educacional no país mudou de modo significativo, pelo fato da universalização do ensino fundamental e a expansão da educação para os níveis médio e superior (Andrade, 2012). 
Tabela 1: Percentual de alunos entrevistados, em 2019, com base nas variáveis pesquisadas.

\begin{tabular}{|c|c|c|c|c|c|c|}
\hline Variáveis & Adm & Agro & Flor & SI & Zoo & Total \\
\hline \multicolumn{7}{|l|}{ Faixa etária (anos) } \\
\hline De 16 a 18 & 15,91 & 14,29 & 10,64 & 25,00 & 22,22 & 16,81 \\
\hline De 19 a 23 & 54,54 & 65,70 & 63,82 & 34,37 & 68,89 & 59,66 \\
\hline De 24 a 27 & 13,64 & 12,86 & 21,28 & 25,00 & 8,89 & 15,55 \\
\hline De 28 a 31 & 9,09 & 0,00 & 4,26 & 6,25 & 0,00 & 3,36 \\
\hline De 32 a 35 & 4,55 & 2,86 & 0,00 & 6,25 & 0,00 & 2,52 \\
\hline De 36 a 42 & 2,27 & 4,29 & 0,00 & 0,00 & 0,00 & 1,68 \\
\hline De 43 ou mais & 0,00 & 0,00 & 0,00 & 3,13 & 0,00 & 0,42 \\
\hline \multicolumn{7}{|l|}{ Gênero } \\
\hline Masculino & 22,73 & 45,16 & 52,50 & 65,62 & 28,57 & 41,82 \\
\hline Feminino & 77,27 & 54,84 & 47,50 & 34,38 & 71,43 & 58,18 \\
\hline \multicolumn{7}{|l|}{ Autodeclaração } \\
\hline Pardo(a) & 72,73 & 64,18 & 73,92 & 71,87 & 64,10 & 68,85 \\
\hline Branco(a) & 9,09 & 23,88 & 6,52 & 15,63 & 20,51 & 15,79 \\
\hline Negro(a) & 18,18 & 11,94 & 17,39 & 12,50 & 10,26 & 14,04 \\
\hline Amarelo(a) & 0,00 & 0,00 & 2,17 & 0,00 & 5,13 & 1,32 \\
\hline \multicolumn{7}{|l|}{ Estado civil } \\
\hline Solteiro(a) & 68,18 & 85,51 & 91,11 & 75,00 & 95,35 & 83,69 \\
\hline Casado(a)/União estável & 25,00 & 14,49 & 8,89 & 15,62 & 4,65 & 13,73 \\
\hline Separado(a)/Divorciado(a) & 6,82 & 0,00 & 0,00 & 9,38 & 0,00 & 2,58 \\
\hline
\end{tabular}

Fonte: Autores.

De acordo com o MEC, no Plano Nacional de Educação e Expansão do Ensino Superior, no período de 2010-2011, a matrícula de estudantes de graduação cresceu 7,9\% em rede pública e 4,8\% na rede privada. Nesse mesmo período também foi identificado um aumento de $10 \%$ na matrícula em rede federal, colaborando com um aumento de mais de 58\% das matrículas na rede pública, superando a marca de 1 milhão de matrículas de graduação.

Segundo Barreto (2014), a universidade tem um papel importante em diversos âmbitos do desenvolvimento brasileiro, além de ser um mecanismo de empoderamento de mulheres e homens, para que ambos estejam capacitados para o mercado profissional. Desde os anos 70, as mulheres ocupam espaços em várias áreas, por meio de lutas por direitos, respeito e reconhecimento. Tendo em vista que no Brasil, a valorização da mulher e a implementação de políticas públicas inclusivas, iniciou-se por volta de 1980 (Farah, 2014).

De acordo com o Censo Demográfico (1970-2000) o avanço nos índices de escolaridade das mulheres ocorreu em todos os níveis educacionais, entretanto, essa evolução foi mais intensa no grupo com nível superior, no qual apenas $25 \%$ eram mulheres em 1970, mas que no ano de 2000, passou a ser predominantemente feminino.

Esse crescimento pode ser evidenciado no presente estudo, no qual a presença do sexo feminino na universidade também é predominante $(58,18 \%$ ) (Tabela 1). Para Guedes (2008), o avanço da participação feminina nas universidades representa uma conquista, independente da forma como esse impacto da melhora na escolaridade, repercutiu na inserção laboral feminina.

De acordo com Heilborn e Sorj (1999, p. 186):

(...) o feminismo contou desde a sua origem com expressivo grupo de acadêmicas, a tal ponto que algumas versões de sua história consideram que o feminismo apareceu primeiro na academia e, só mais tarde, teria se disseminado entre 
mulheres com outras inserções sociais. As acadêmicas, por sua maior exposição a ideias que circulam internacionalmente, estavam numa posição privilegiada para receber, elaborar e disseminar as novas questões que o feminismo colocara já no final da década de sessenta nos países capitalistas avançados. Assim, quando o movimento de mulheres no Brasil adquire visibilidade, a partir de 1975, muitas das suas ativistas ou simpatizantes já estavam inseridas e trabalhavam nas universidades.

Todavia, sabe-se que a equidade entre mulheres e homens ainda é pauta, quando se trata de políticas públicas e sociais, não só pelo Estado, mas também em agenda de políticas públicas de organizações de nível internacional, dentre elas, a Organização das Nações Unidas (ONU), a Organização das Nações Unidas para a Educação, a Ciência e a Cultura (UNESCO) e a Organização de Telecomunicações da Ibero-américa (OTI) (Barreto, 2014).

A predominância de alunos pardos autodeclarados de $(68,85 \%)$ (Tabela 1), pode ser justificada pelo fato de que a maioria dos alunos já eram residentes do município de Paragominas (60,34\%) (Tabela 3). Dos discentes que não residiam no município antes de ingressar na universidade, 35,86\% moravam em outros municípios do estado do Pará, que segundo o Censo Demográfico (2010), apresentam uma população majoritariamente parda.

A maioria dos alunos entrevistados $(83,69 \%)$, se autodeclaram solteiros (Tabela 1). Esse fato pode ser interpretado pela perspectiva de que atualmente os jovens priorizam ter uma qualificação profissional. Tanto homens quanto mulheres, estão preferindo investir nos estudos e optando por deixar o casamento para um momento em que haja estabilidade financeira entre o casal (Zordan, et. al., 2009).

Em meados do século XX foram percebidas iniciativas que resultaram na conquista de direitos para as pessoas com deficiência, para incentivar a integração (Mazzota, 1996). De modo geral, embora se progredisse em práticas sociais menos cruéis, a separação, a estigmatização e a desvalorização, marcaram a história da deficiência em algumas sociedades antigas, assim como no mundo ocidental. O processo não foi diferente no Brasil, na qual práticas semelhantes estiveram presentes na história da educação especial (Fernandes, 2015).

Na Tabela 2, pode-se observar que 97,85\% dos alunos matriculados na universidade, não apresentam deficiência e que apenas $2,15 \%$ dos discentes entrevistados, possuem deficiência, sendo um deficiente auditivo e outro visual.

Tabela 2: Percentual de alunos entrevistados, em 2019, por pessoas com deficiência(s).

\begin{tabular}{lcccccc}
\hline Deficiência & Adm & Agro & Flor & SI & Zoo & Total \\
\hline Não & 93,02 & 100,00 & 97,78 & 100,00 & 97,73 & 97,85 \\
Sim* & 6,98 & 0,00 & 2,22 & 0,00 & 2,27 & 2,15 \\
\hline Total & 100,00 & 100,00 & 100,00 & 100,00 & 100,00 & 100,00 \\
\hline
\end{tabular}

* Somente dois alunos de administração identificaram o tipo de deficiência, um possui necessidade visual e o outro auditiva. Fonte: Autores.

A inclusão de jovens com deficiência tornou-se presente nos meios acadêmicos, políticos e sociais, ficando evidente os resultados gerados pelas políticas de inclusão. De acordo com Fernandes (2015), a discussão acerca dos processos inclusivos dentro das IES é necessária, pois a inclusão vem sendo um grande desafio que se manifesta gradativamente em diferentes níveis de ensino ou instituições.

Segundo dados da Secretaria Nacional de Pessoa com Deficiência (SNPD, 2013), houve uma evolução no índice de matrículas de estudantes com deficiência no ensino superior, que considerando o ano de 2003 como um ponto de partida, com 5.078 pessoas deficientes matriculadas e que ao longo dos anos se impulsionou, chegando a marcar no ano de 2011, um total de 23.250 matriculados, distribuídos em instituições públicas e privadas. Em relação a moradia, observa-se que 36,70\% dos alunos entrevistados moram com os pais, seguido de $14,35 \%$ representando aqueles que moram somente com a mãe ou com o pai (Tabela 3). 
Quanto à situação de moradia, observa-se que 46,16\% dos alunos moram em casa própria. Este resultado pode ser justificado pelo fato da maioria dos discentes residirem no município de Paragominas e morarem com os seus pais (Tabela 3).

Nos dias de hoje, o ingresso na universidade não se configura como sinônimo de saída da casa dos pais, já que a interiorização do ensino superior, está permitindo que os jovens frequentem a universidade sem necessariamente, mudar de cidade (Cervinski \& Enricone, 2012). A moradia, compõem o ambiente acadêmico, trazendo contribuições importantes para a sua formação (Garrido, 2012). Neste sentido, o apoio familiar, ajuda os alunos a se dedicarem mais aos estudos, pois as responsabilidades com as contas e afazeres domésticos, são divididas com os demais membros da família.

Tabela 3: Percentual de alunos entrevistados, em 2019, por variáveis relacionadas a moradia.

\begin{tabular}{|c|c|c|c|c|c|c|}
\hline Variáveis & Adm & Agro & Flor & SI & Zoo & Total \\
\hline \multicolumn{7}{|c|}{$\underline{\text { Residia em outra localidade antes de ingressar na universidade }}$} \\
\hline Não & 68,18 & 57,97 & 53,19 & 81,25 & 48,89 & 60,34 \\
\hline Sim, em outro estado & 2,27 & 4,35 & 6,38 & 0,00 & 2,22 & 3,38 \\
\hline Sim, em outra cidade & 29,55 & 37,68 & 38,30 & 18,75 & 48,89 & 35,86 \\
\hline Sim, em outro país & 0,00 & 0,00 & 2,13 & 0,00 & 0,00 & 0,42 \\
\hline \multicolumn{7}{|l|}{ Situação de moradia } \\
\hline Com os pais & 36,36 & 27,14 & 39,12 & 43,74 & 44,45 & 36,70 \\
\hline Com a mãe ou pai & 6,82 & 22,86 & 8,70 & 15,63 & 13,33 & 14,35 \\
\hline Com familiars & 9,09 & 15,71 & 13,04 & 18,75 & 8,89 & 13,08 \\
\hline Com cônjuge /companheiro(a) & 27,27 & 14,29 & 8,70 & 9,38 & 2,22 & 12,66 \\
\hline Sozinho(a) & 13,64 & 10,00 & 8,70 & 12,50 & 17,78 & 12,24 \\
\hline Divide aluguel com amigos & 2,27 & 7,14 & 10,87 & 0,00 & 11,11 & 6,75 \\
\hline Casa de amigos & 4,55 & 2,86 & 10,87 & 0,00 & 2,22 & 4,22 \\
\hline \multicolumn{7}{|l|}{ Moradia } \\
\hline Própria & 50,00 & 36,23 & 43,48 & 75,00 & 40,00 & 46,19 \\
\hline Alugada & 18,18 & 42,03 & 34,78 & 12,50 & 37,78 & 31,35 \\
\hline Cedida & 20,46 & 8,70 & 15,22 & 6,25 & 13,33 & 12,71 \\
\hline Própria em pagamento & 11,36 & 13,04 & 6,52 & 6,25 & 8,89 & 9,75 \\
\hline \multicolumn{7}{|l|}{ Aluguel } \\
\hline Não & 90,70 & 76,92 & 78,57 & 96,87 & 75,61 & 82,51 \\
\hline Sim & 9,30 & 23,08 & 21,43 & 3,13 & 24,39 & 17,49 \\
\hline \multicolumn{7}{|l|}{ Meio } \\
\hline Ônibus & 72,73 & 78,57 & 85,11 & 59,38 & 73,33 & 76,05 \\
\hline Motocicleta & 18,18 & 10,00 & 6,38 & 37,50 & 8,89 & 14,29 \\
\hline Carro próprio & 4,55 & 7,14 & 4,26 & 3,13 & 13,33 & 6,72 \\
\hline Carona & 4,55 & 4,29 & 0,00 & 0,00 & 4,44 & 2,94 \\
\hline Bicicleta & 0,00 & 0,00 & 2,13 & 0,00 & 0,00 & 0,42 \\
\hline Van & 6,82 & 0,00 & 0,00 & 3,13 & 0,00 & 1,68 \\
\hline A pé & 2,27 & 0,00 & 2,13 & 0,00 & 2,22 & 1,26 \\
\hline
\end{tabular}

Fonte: Autores. 
Entretanto, os resultad.os apontam que 31,36\% dos alunos moram de aluguel, dentre estes estudantes, grande parte está representado por aqueles que se deslocaram de seu contexto familiar, para ingressarem na universidade. Quando questionados sobre a divisão de aluguel, 82,51\% dos alunos não dividem aluguel (Tabela 3).

Na Tabela 4, pode-se observar que os alunos pagam em média \$213, 16 reais por mês na divisão de aluguel.

Tabela 4: Percentual de alunos entrevistados, em 2019, por valor pago por pessoa na divisão do aluguel.

\begin{tabular}{lcccc}
\hline Estatísticas & Adm & Agro & Flor & Zoo \\
\hline Mínimo & 100,00 & 87,50 & 83,33 & 100,00 \\
Média & 205,00 & 204,61 & 167,75 & 275,27 \\
Erro padrão & 44,06 & 14,32 & 31,67 & 39,26 \\
Mediana & 210,00 & 200,00 & 179,00 & 275,00 \\
Moda & - & 200,00 & 83,33 & 275,00 \\
Coeficiente de variação (\%) & 42,99 & 26,18 & 53,40 & 47,30 \\
Máximo & 300,00 & 300,00 & 350,00 & 500,00 \\
\hline
\end{tabular}

*Alunos de Sistemas de Informação não informaram os valores. Fonte: Autores.

Em relação ao deslocamento até a universidade, os meios de transportes mais frequente utilizados pelos alunos é o transporte público $(76,05 \%)$, seguido da motocicleta $(14,29 \%)$ e de carro próprio $(6,72 \%)$ (Tabela 3$)$. O ônibus é um meio de transporte fundamental, tanto para as pessoas que residem longe do local de trabalho, quanto para os alunos que não dispõem de recursos financeiros, para obter outros meios de transporte que exigem maior investimento (Barrinha, 2017). Para os alunos que fazem uso do transporte público, é assegurado a meia passagem estudantil. Este direito é concedido a todos os alunos de instituições públicas e privadas, com intuito de ajudar os estudantes com poucos recursos financeiros a terem acesso à educação.

Evidenciou-se que a média de alunos sem vínculo empregatício é de 36,28\%, seguido de 34,18\% que nunca trabalharam (Tabela 5). Esta situação, possivelmente está relacionada com o fato da maioria serem mais jovens, e isto acaba se tornando um fator que dificulta o seu ingresso no mercado de trabalho, pois a maioria das empresas, buscam preferencialmente, por pessoas qualificadas e com experiência profissional. O que não se encaixa na realidade destes alunos, pois a maioria ingressou diretamente do ensino médio para o ensino superior.

Um curso de graduação exige desempenho e dedicação, tanto durante as aulas, como também nas atividades extracurriculares. Desta forma, conciliar a vida profissional com a vida acadêmica se torna um desafio. Esta rotina cansativa de trabalho e estudo, dificulta o processo de leitura, reflexão, pesquisa e aprendizagem (Brito, et.al. 2007), o que pode favorecer para a redução do nível de envolvimento com o meio acadêmico. Por estarem desempregados estes alunos acabam dependendo financeiramente de seus pais (Tabela 5).

Como os alunos não conseguem conciliar os estudos com o trabalho, o auxílio acadêmico, quando remunerado, tornase uma fonte de contribuição de renda. Quando questionados sobre recebimento de auxilio acadêmico, 79,24\% afirmaram não receber nenhum tipo de auxílio, sendo apenas 20,76\% que recebem algum tipo de auxílio financeiro (Tabela 5). O auxilio acadêmico tem como objetivo contribuir para a formação integral dos alunos, muito deles com dificuldades financeiras, acabam desistindo de sua formação profissional. A política de assistência estudantil, objetiva a igualdade de oportunidades para os estudantes, de forma a combater a evasão das instituições (Reuni, 2007). Nesse sentido, a assistência estudantil é uma ferramenta de suma importância, pois cria ações de apoio aos estudantes, ações estas que vão desde condições de acesso aos instrumentos necessários à formação profissional, até a geração de recursos mínimos para a sobrevivência (Estrada \& Radaelli, 2014).

Com o crescimento das políticas públicas de incentivos a expansão do ensino superior, como o Programa de Reestruturação e Expansão das Universidades Federais (Reuni) em 2007, o Sistema de Seleção Unificada (SiSU) e a criação da Lei de Cotas em 2012, que tem a finalidade reservar uma parte das vagas em todos os cursos de graduação para os alunos que 
tenham cursado o ensino médio em escolas públicas, pardos, pretos, indígenas e de baixa renda, permitiu que estudantes de diferentes classes sociais, etnias e gêneros, obtivessem a oportunidade de obter uma vaga no ensino superior (Neves, et.al., 2018).

No entanto, as desigualdades entre os alunos dentro das IES, é relevante, o que torna um problema e favorece para a desistência ou trancamento do curso. Com o objetivo de minimizar esses impactos e auxiliar na permanência desses alunos nos cursos de graduação, o governo federal criou o Plano de Assistência Estudantil (PNAES), para fornecer auxílios financeiros, moradia, alimentação, transporte e pedagógico. O PNAES emergencial (39,59\%), PNAES transporte (14,58\%), PNAES pedagógico (14,58\%) e PNAES alimentação (12,50\%), obtiveram maiores percentuais entre os alunos entrevistados (Tabela 5).

Tabela 5: Percentual de alunos entrevistados, em 2019, por situação de trabalho remunerado e recebimento de auxílio.

\begin{tabular}{|c|c|c|c|c|c|c|}
\hline Variáveis & Adm & Agro & Flor & SI & Zoo & Total \\
\hline \multicolumn{7}{|l|}{ Situação de emprego } \\
\hline Desempregado(a) & 40,91 & 37,14 & 42,55 & 34,38 & 25,00 & 36,28 \\
\hline Nunca trabalhou & 18,18 & 41,42 & 34,04 & 12,50 & 54,54 & 34,18 \\
\hline Empregado(a) & 34,09 & 14,29 & 10,64 & 40,62 & 2,27 & 18,57 \\
\hline Autônomo(a) & 6,82 & 7,15 & 12,77 & 12,50 & 18,19 & 10,97 \\
\hline \multicolumn{7}{|l|}{ Orçamento familiar } \\
\hline Depende financeiramente dos pais & 45,24 & 74,28 & 77,78 & 49,98 & 86,68 & 68,81 \\
\hline $\begin{array}{l}\text { Independente financeiramente e responsável por parte das } \\
\text { despesas domésticas }\end{array}$ & 19,05 & 4,29 & 4,44 & 21,88 & 2,22 & 8,97 \\
\hline $\begin{array}{l}\text { Independente financeiramente e custeia apenas suas despesas } \\
\text { pessoais }\end{array}$ & 16,67 & 2,86 & 6,67 & 9,38 & 4,44 & 7,26 \\
\hline Depende do cônjuge ou companheiro & 11,90 & 10,00 & 4,44 & 3,13 & 2,22 & 6,84 \\
\hline $\begin{array}{l}\text { Independente financeiramente e responsável por todas as } \\
\text { despesas domésticas }\end{array}$ & 4,76 & 5,71 & 6,67 & 9,38 & 0,00 & 5,13 \\
\hline Depende financeiramente de outros parentes & 2,38 & 2,86 & 0,00 & 6,25 & 4,44 & 2,99 \\
\hline \multicolumn{7}{|l|}{ Recebimento de auxílio na universidade } \\
\hline Não & 88,64 & 70,00 & 67,39 & 96,87 & 84,09 & 79,24 \\
\hline Sim & 11,36 & 30,00 & 32,61 & 3,13 & 15,91 & 20,76 \\
\hline \multicolumn{7}{|l|}{ Auxílio recebido } \\
\hline PNAES (Sem descrição do tipo) & 0,00 & 40,00 & 26,67 & 100,00 & 85,71 & 39,59 \\
\hline PNAES emergencial & 20,00 & 10,00 & 26,67 & 0,00 & 0,00 & 14,58 \\
\hline PNAES transporte & 0,00 & 25,00 & 13,33 & 0,00 & 0,00 & 14,58 \\
\hline PNAES pedagógico & 20,00 & 10,00 & 13,33 & 0,00 & 14,29 & 12,50 \\
\hline PNAES alimentação & 20,00 & 10,00 & 13,33 & 0,00 & 0,00 & 10,42 \\
\hline PNAES moradia & 40,00 & 0,00 & 0,00 & 0,00 & 0,00 & 4,17 \\
\hline PNAES moradia e alimentação & 0,00 & 5,00 & 0,00 & 0,00 & 0,00 & 2,08 \\
\hline PNAES pedagógico e creche & 0,00 & 0,00 & 6,67 & 0,00 & 0,00 & 2,08 \\
\hline \multicolumn{7}{|l|}{ Participação em programa social do governo } \\
\hline Não & 97,73 & 97,14 & 89,13 & 93,75 & 95,56 & 94,94 \\
\hline Sim (bolsa família) & 2,27 & 2,86 & 10,87 & 6,25 & 4,44 & 5,06 \\
\hline
\end{tabular}

Fonte: Autores. 
Observa-se que 94,94\% dos alunos entrevistados, não recebiam nenhum tipo de benefício de programa social do governo federal (Tabela 5). Esse fato, pode ser justificado em função da idade dos alunos, a maioria 59,66\% (Tabela 1) tinham entre 19 a 23 anos de idade. O principal programa social do governo federal é o Bolsa Família, que preferencialmente contemplam, mães de família com crianças e adolescentes abaixo de 18 anos.

Além da criação do Plano de Assistência Estudantil (PNAES), foram implementadas outras políticas de incentivo a permanência e o desenvolvimento intelectual dos alunos. As atividades acadêmicas como o Programa Institucional de Bolsas de Iniciação de Iniciação Científica (PIBIC), o Programa de Educação Tutorial (PET), as monitorias, sendo algumas remuneradas, a criação de Empresa júnior, estágios e muitos outros, não têm como função proporcionar somente auxílio financeiro, eles fomentam o desenvolvimento tecnológico, estimula o ensino, a pesquisa e a extensão.

Em relação as atividades acadêmicas $71,67 \%$ dos alunos entrevistados, não participavam de nenhuma atividade (Tabela 6). Dos alunos que participavam, a maior parte, 36,36\% desenvolviam pesquisa, 33,33\% estágios, 18,18\% integravam o PET e 15,15\% a Empresa júnior (Tabela 6). Quando questionados se recebiam algum tipo de remuneração pelo desenvolvimento das atividades, 83,80\%, afirmaram exercer as atividades de forma voluntária (Tabela 6).

Tabela 6: Percentual de alunos entrevistados, em 2019, por participação de atividade acadêmica.

\begin{tabular}{lcccccc}
\hline Variáveis & Adm & Agro & Flor & SI & Zoo & Total \\
\hline Participação & \multicolumn{7}{c}{} & & & & \\
\hline Não & 88,64 & 52,94 & 77,78 & 84,38 & 68,18 & 71,67 \\
Sim & 11,36 & 47,06 & 22,22 & 15,63 & 31,82 & 28,33 \\
\hline Tipo de atividade & & & & & & \\
\hline Pesquisa & 40,00 & 43,75 & 10,00 & 60,00 & 28,57 & 36,36 \\
Estágio & 0,00 & 25,00 & 80,00 & 40,00 & 28,57 & 33,33 \\
PET & 0,00 & 0,00 & 80,00 & 40,00 & 7,14 & 18,18 \\
Empresa junior & 60,00 & 12,50 & 0,00 & 0,00 & 21,43 & 15,15 \\
Extensão & 80,00 & 0,00 & 10,00 & 20,00 & 0,00 & 12,12 \\
Ensino & 0,00 & 9,38 & 0,00 & 0,00 & 7,14 & 6,06 \\
\hline Atividade remunerada & & & & & & 83,80 \\
Não & 97,67 & 68,97 & 45,45 & 96,87 & 77,78 & 16,20 \\
Sim & 2,33 & 31,03 & 54,55 & 3,13 & 22,22 & \\
\hline
\end{tabular}

Fonte: Autores.

Com base no exposto, fica evidente que a expansão e as políticas de incentivos ao ensino superior, são essenciais para que jovens e adultos, tenham acesso a uma vaga de graduação nas diferentes IES (Freitag \& Rubin-Oliveira, 2015). Os pontos positivos, são inúmeros, a educação proporciona que as pessoas possam obter uma melhor qualificação profissional e, consequentemente, maiores salários, melhor qualidade de vida e redução da taxa de desemprego. Entretanto, ressalta-se a importância de se conhecer a realidade dos estudantes e de medidas de assistência estudantil, para reduzir as desigualdades sociais e com isso, proporcionar sua permanência e conclusão do curso.

\section{Conclusão}

Diante de uma perspectiva transformadora, e real, a presente pesquisa permitiu apresentar alguns aspectos das dificuldades encontradas na vida social e econômica de discentes da universidade pública. E por se tratar de um problema de 
grande dimensão, é importante levantar a discussão, questionamentos, visando conhecer melhor esta situação que afeta toda uma comunidade acadêmica. As intervenções econômicas sociais nas universidades federais, podem não proporcionar mudanças extremas, no entanto, servem como mediadores para a realização de ações que venham contribuir para a reafirmação do papel destes discentes como cidadãos e participantes responsáveis pela mudança da sua realidade.

Concluiu-se que a maioria dos alunos se encontram na faixa etária de 19 a 23 anos, são do gênero feminino, se autodeclaram pardos(as), solteiros(as) e moram com os pais. Dos que pagam aluguel, gastam em média $\$ 213,16$ por mês.

A maior parte dos alunos, andam de transporte público, estão desempregados, dependem financeiramente dos pais, não recebem auxílio acadêmico e nem fazem parte de programas sociais do governo. A maioria não participa de atividades acadêmicas e dos que participam, apenas $16,20 \%$ são remunerados.

Diante do exposto, é importante que sejam realizados mais estudos sobre essa situação, pois dessa forma será possível identificar os principais fatores que causam a evasão do Ensino Superior, a fim de criar políticas de ações afirmativas, como estratégias de enfrentamento aos problemas apontados.

\section{Referências}

Agapito, A. P. (2016). Ensino superior no Brasil: expansão e mercantilização na contemporaneidade. Temporalis. 16 (32), 123-140. https://dialnet.unirioja.es/servlet/articulo?codigo=5910924

Barreto, A. (2014). A mulher no ensino superior distribuição e representatividade. Cadernos do GEA, 3(6). 5-46. http://flacso.org.br/files/2016/04/caderno_gea_n6_digitalfinal.pdf

Barrinha, J. E. S. (2017). Transporte coletivo urbano por ônibus em Teresina: Da implantação à integração. Pós-Graduação, Universidade Federal do Piauí, Teresina. https://repositorio.ufpi.br/xmlui/bitstream/handle/123456789/1172/JOS\%c3\%89\%20EDSON\%20DA\%20SILVA\%20BARRINHA.pdf?sequence=1

Brasil. (2012). Lei n ${ }^{\circ}$ 12.711, de 29 de agosto de 2012. Dispõe sobre o ingresso nas universidades federais e nas instituições federais de ensino técnico de nível médio e dá outras providências. Diário Oficial da União, Brasília, DF. http://www.planalto.gov.br/ccivil_03/_ato2011-2014/2012/lei/112711.htm

Brasil. (2013). Ministério da Educação. SNDPD - Secretaria Nacional dos Direitos da Pessoa com Deficiência. Referências de acessibilidade na educação superior e a avaliação in loco do sistema nacional de avaliação da educação superior (SINAES). Brasília. https://prograd.ufc.br/wpcontent/uploads/2013/11/referenciais-de-acessibilidade-inep-mec-2013.pdf

Brasil. (2016). LEI n 13409, de 28 de dezembro de 2016. Dispõe sobre a reserva de vagas para pessoas com deficiência nos cursos técnico de nível médio e superior das instituições federais de ensino. Diário Oficial da União, Brasília, DF. http://www.planalto.gov.br/ccivil_03/_ato2015-2018/2016/lei/113409.htm

Brasil. MEC. Instituto Nacional de Estudos e Pesquisas Educacionais (Inep). (2012). Plano Nacional de Educação e Expansão da Educação Superior. http://portal.mec.gov.br/index.php?option=com_docman\&view=download\&alias=12082-apresentacao-inep-pdf\&category_slug=dezembro-2012pdf\&Itemid=30192

Brasil. Ministério da Educação; REUNI. Reestruturação e Expansão das Universidades Federais (2007). Diretrizes Gerais. http://portal.mec.gov.br/sesu/arquivos/pdf/diretrizesreuni.pdf

Brito, L. M. P, Souza, T. \& Oliveira, P. W. S. (2007). O mestrando que trabalha - como estimular e criar condições favoráveis de leitura em tempo escasso? Anais eletrônicos Recife: ANPAD. http://www.anpad.org.br/ anpad/eventos.php?cod_evento=18\&cod_edicao_subsecao=307\&

Carvalho, M. M. \& Waltenberg, F. D. (2015). Desigualdade de oportunidades no acesso ao ensino superior no brasil: uma comparação entre 2003 e 2013. Economia Aplicada, 19(2), 369-396. Doi: https://doi.org/10.1590/1413-8050/ea124777

Cervinski, L. F. \& Enricone, J. R. B. (2012). Percepção de calouros universitários sobre o processo de adaptação ao sair da casa dos pais. Perspectiva, 36(136), https://www.uricer.edu.br/site/pdfs/perspectiva/136_311.pdf

Estrada, A. \& Radaelli, A. (2014). A política de assistência estudantil em uma universidade pública; a perspectiva estudantil. Revista on-line de Política e Gestão Educacional, 1(16), 32-47. Doi: https://doi.org/10.22633/rpge.v0i16.9359

Farah, M. F. S. Gênero e políticas públicas. (2014). Revista Estudos Feministas, 12(1), 47-71. Doi: https://doi.org/10.1590/S0104-026X2004000100004

Fernandes, A. C. R. (2015). Dinâmicas de significação e trajetórias de desenvolvimento: experiências de estudantes com deficiência autodeclarada na universidade. Tese (Doutorado). Universidade Brasília. http://repositorio.se.df.gov.br/bitstream/123456789/1020/1/2015_AnaClaudiaRodriguesFernandes.pdf

Freitag, B. E. B.\& Rubin-Oliveira, M. (2015). Políticas de permanência: um estudo na UTFPR Campus Pato Branco/PR. Revista de Ciências Humanas: Educação, 16(27), 38-55. http://revistas.fw.uri.br/index.php/revistadech/article/view/1675/1931

Garrido, E. N. (2012). Moradia estudantil e formação do (a) estudante universitário (a). Tese (doutorado). Universidade Estadual de Campinas, Campinas. http://bdtd.ibict.br/vufind/Record/CAMP_f316a3189f34773cd15daaa3c4ac4fb1 
Research, Society and Development, v. 11, n. 1, e1211124169, 2022

(CC BY 4.0) | ISSN 2525-3409 | DOI: http://dx.doi.org/10.33448/rsd-v11i1.24169

Guedes, M. C. (2008). A presença feminina nos cursos universitários e nas pós-graduações: desconstruindo a ideia da universidade como espaço masculino. História, Ciências, Saúde - Manguinhos, 15 (1), 117-132. Doi: https://doi.org/10.1590/S0104-59702008000500006

Heilborn, M. L.\& SORI, B. (1999). Estudos de gênero no Brasil. In: MICELI, Sérgio (Org.). O que ler na ciência social brasileira (1970-1995). Anpocs/Capes, 1(1),183-221. http://www.clam.org.br/bibliotecadigital/uploads/publicacoes/102_653_EstudosdeGeneronoBrasil1.pdf

Instituto Brasileiro de Geografia e Estatística (IBGE). (2010). Estatísticas de Gênero. Uma análise do Censo Demográfico, 2010. http://biblioteca.ibge.gov.br/visualizacao/ livros/liv88941.pdf

Mazzota, M. J. S. (1996). Educação Especial no Brasil: história e políticas públicas. São Paulo. Cortez ,6ª edição, p.232.

Natividade, R. C. (2014). Juventude, educação e desenvolvimento: o caso do Paranoá e as políticas públicas de acesso ao ensino superior no Brasil contemporâneo. Dissertação (Mestrado em Desenvolvimento, Sociedade e Cooperação Internacional) —Universidade de Brasília, Brasília. https://repositorio.unb.br/bitstream/10482/19536/1/2014_RubenilsonCerqueiradeNatividade.pdf

Neves, C. E.; Sampaio, H. \& Heringer, R. (2018). A institucionalização da pesquisa sobre ensino superior no Brasil. Revista Brasileira de Sociologia, 6(12), 19 - 41. Doi: https://doi.org/10.20336/rbs.243

Queiroz, Z. C. L. S.; Miranda, G. J.\& Tavares, M.; Freitas, S. C. (2015). A lei de cotas na perspectiva do desempenho acadêmico na Universidade Federal de Uberlândia. Revista Brasileira Estudos Pedagógicos (online), 96(243), 299-320.Doi: https://doi.org/10.1590/S2176-6681/339112863

Rodrigues, D. S.; Santos, N. A.; Santana, M. S.\& Lemes, A. P. M. (2017). Diferenças entre gênero, etnia e perfil socioeconômico no exame nacional de desempenho do estudante do curso de ciências contábeis. Revista Contemporânea de Contabilidade. 14(33),101-117. Doi: https://doi.org/10.5007/21758069.2017v14n33p101

Tachibana, T. Y.; Menezes-Filho. A, N.\& Komatsu, B. K. (2015). Ensino superior no Brasil. Policy Paper, 1(14), 1 - 53. https://www.insper.edu.br/wpcontent/uploads/2018/09/Ensino-superior-no-Brasil.pdf

Zordan. E.P.; Falker. D. \& Wagner. A. (2009). Casar ou não casar? Motivos e expectativas com relação ao casamento. Psicologia em Revista, 15(2), 56-76. http://pepsic.bvsalud.org/scielo.php?script=sci_arttext\&pid=S1677-11682009000200005 